AARP

\title{
Our Collective Future: \\ The Economic Impact of Unequal Life Expectancy
}

Racial disparities in life expectancy could cost the U.S. economy $\$ 1.6$ trillion in 2030
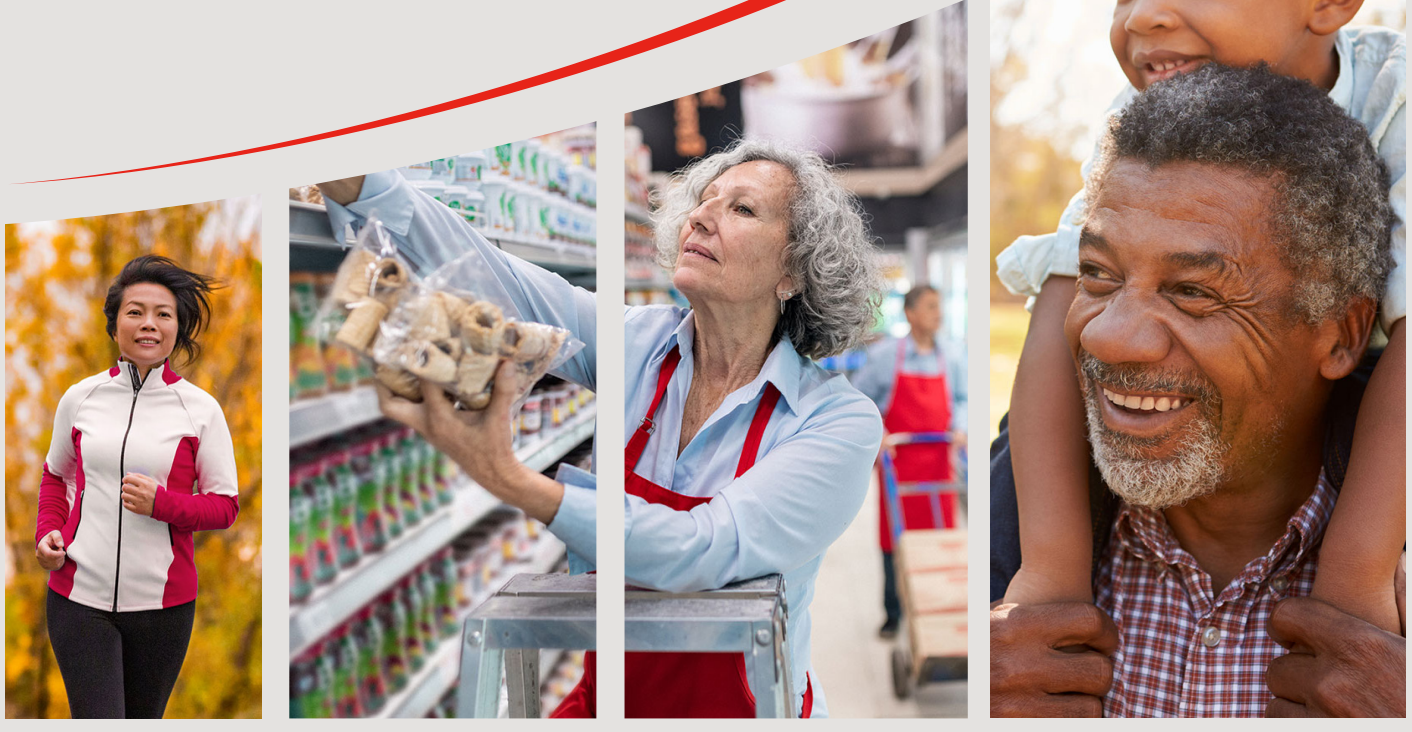


\section{Contents}

Background

Executive summary

Disparity in life expectancy in the U.S.

6

Economic costs of racial disparities in life expectancy

Closing the racial gap in life expectancy

Final thoughts

Appendix 1 


\section{Background}

There is a large and widespread longevity gap in the United States.

When it comes to how long you will live, where you live matters. The general environment and conditions in which people live, learn, work, play, worship, and age have tremendous influence on their health and longevity. People of color disproportionately live, work, and play in communities with health challenges and, therefore, differences in neighborhood characteristics are a major factor that explains the poorer health of many minority groups relative to the general population.

People of color face significant structural barriers to healthcare access-from living in communities with inadequate healthcare resources to dealing with racial bias in encounters with healthcare providers, receiving poorer quality care in nursing homes, and more. Disparities disrupt people's ability to live longer, healthier, and more productive lives.

They rob individuals of what they need and rely on to maintain good health, become financially resilient, live as long as possible, and age as they choose. These same disparities stifle economic growth and everyone suffers as a result. To eliminate disparities requires disruption of the systems that sustain inequity.

What would it take for all of us to live longer and reach our fullest potential? As we envision a post-pandemic world, our goal should be greater equity for all. The COVID-19 pandemic revealed major systemic and infrastructure weaknesses in the core foundation of society. As the crisis spread across the world, two notable developments took hold: First, the pandemic hit older people much harder than other age cohorts. Second, people of color experienced higher rates of infections, hospitalization, and death due to COVID-19, largely attributable to structural inequities. These structural inequities account for disparities within social determinants of health and the health status of certain racial/ ethnic groups and include residential segregation, rural isolation, generational poverty, and disparities in access to quality health care, education, and community livability. Certain groups are especially vulnerable to experiences of structural inequities-people of color, older adults, members of the LGBTQ community, and people with disabilities.

This report seeks to calculate the continued and cumulative economic costs of racial disparities in life expectancy, while also emphasizing the human and societal costs. Moreover, it demonstrates that ensuring we all have the same number of years to grow old with our spouses, play cards with our friends, and watch our grandchildren grow up is not only good for individuals - it benefits society, government, and business.

\section{What would it take for all of us to live longer and reach our fullest potential? As we envision a post-pandemic world, our goal should be greater equity for all.}

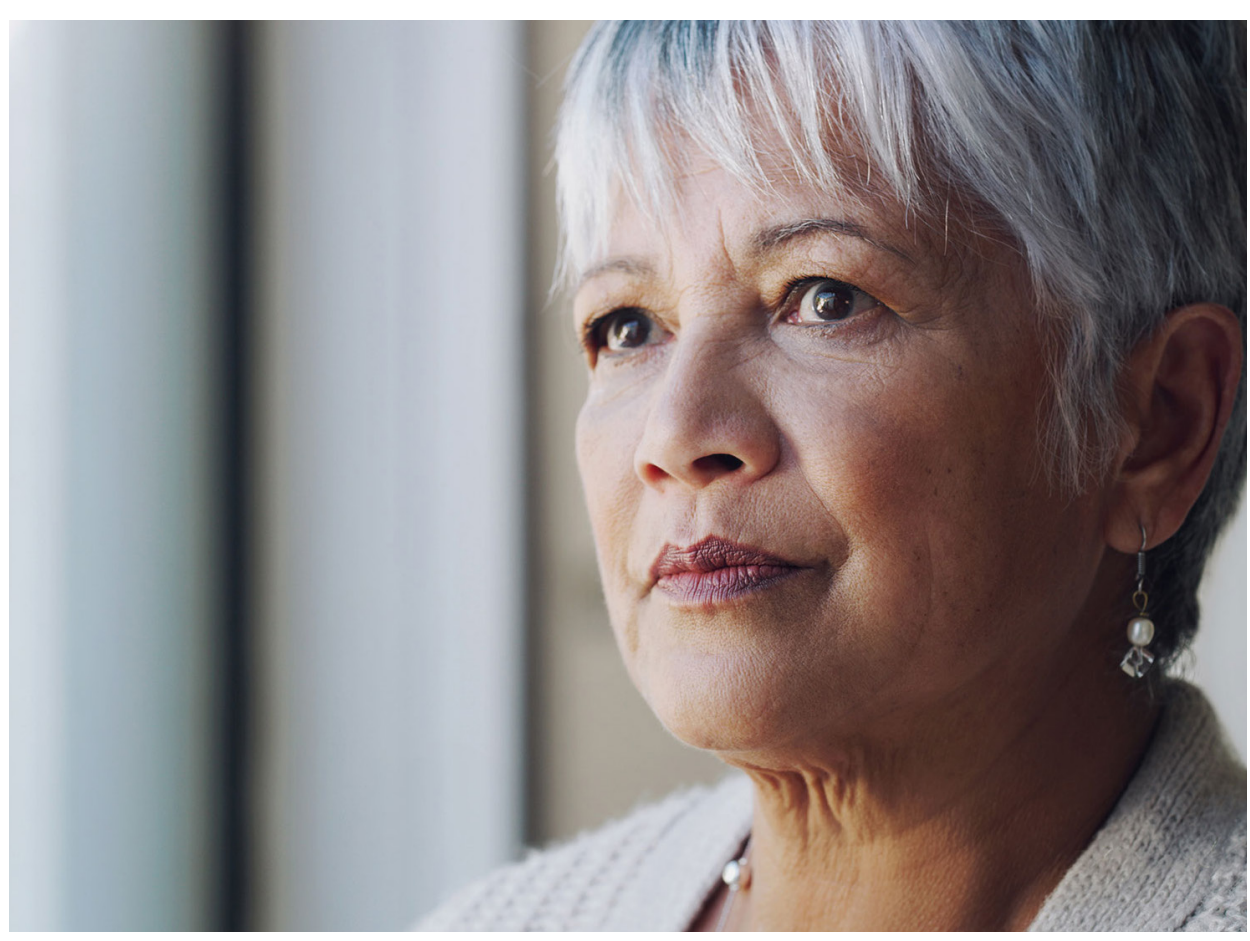




\section{Executive summary}

This report explores the question: What is the total economic cost of current racial and ethnic disparities on life expectancy in the United States?

It discusses the size and scope of current disparities in life expectancy, the socioeconomic factors that give rise to these inequalities, and the resulting costs to the economy.

The COVID-19 pandemic has resulted in a disproportionate number of deaths among Black/African Americans (NonHispanic Black people) and Latino/ Hispanic people (Hispanic people of all races) in the United States, together with job losses and business failures that also have disproportionately affected these communities. These disparities have not occurred randomly, but rather COVID-19 has exacerbated longstanding structural issues. For example, Black people in 2019 could expect to live 4.1 years less than the average person in the U.S.' This gap rose to 5.5 years in 2020. Meanwhile, Latino people-who had a higher life expectancy at birth than White (Non-Hispanic White) people from 1999 to 2020_saw this difference shrink from 3.0 years to 1.2 years.

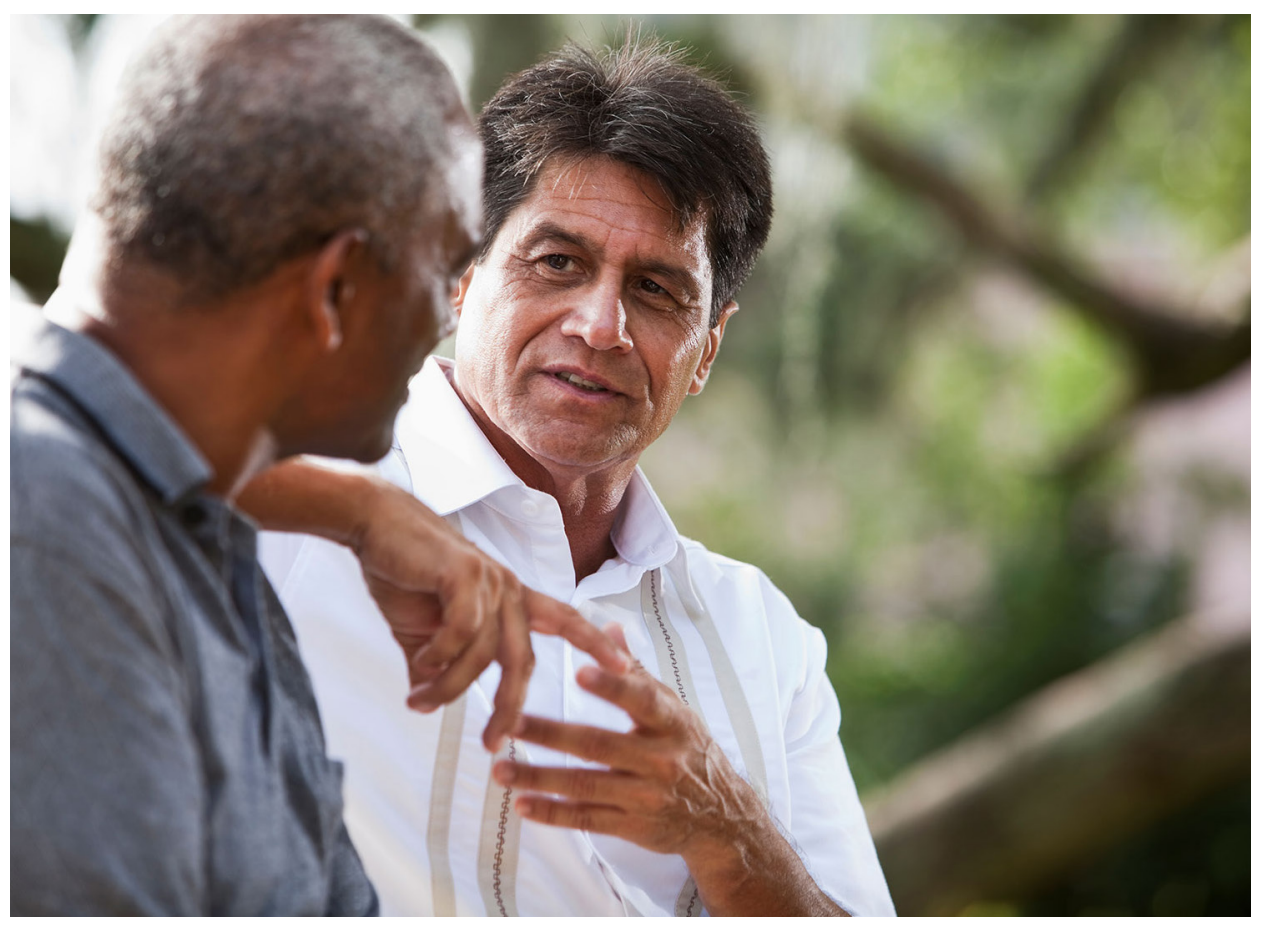

In exploring the total economic cost of current racial/ethnic disparities on life expectancy, we define the cost in terms of a counterfactual comparison. The analysis measures the total cost of these disparities by estimating the size of the gap between two contrasting scenarios:

1. Baseline scenario: a decade (2022-2030) with no changes to expected disparities, versus

\section{Counterfactual scenario:}

a decade with fully equal life expectancy outcomes between the racial/ethnic groups.
Using the results of this comparison, we discuss the broader economic costs imposed by these disparities, including their impact on GDP, jobs, wages, the population, and various economic sectors. These findings highlight how the U.S. is missing out on significant and cumulative benefits as a result of its racial and ethnic inequities in longevity. With the events of 2020 highlighting just how significant these disparities are, we must urgently act as a society to close these gaps in life expectancy. Policymakers, businesses, and individuals across the country need to work together to construct a future that strengthens health and builds wealth through increased equity in longevity. 
Key findings

The annual economic cost to U.S. GDP caused by racial disparities in life expectancy is expected to reach \$1.6 trillion in 2030 (5.1 percent of projected GDP_equivalent to the combined size of Massachusetts' and Virginia's economies in 2030).

Racial disparities in life expectancy will cost the U.S. an estimated 10.1 million jobs in 2030 (4.9 percent of the total) and $\$ 934$ billion in wages and salaries (4.9 percent of the total).

Disparities in life expectancy could result in an annual loss of $\$ 1.1$ trillion in total consumer spending by $\mathbf{2 0 3 0}$. Impacts will be felt most for products commonly purchased by older adults, including financial services and insurance (8.0 percent), heath care (6.5 percent), motor vehicles (5.9 percent), transportation services (7.4 percent), and technology (7.1 percent).
The costs of unequal life expectancy are not equally distributed across the country or the economy. These negative effects hit some groups and regions much harder than others-in particular, regions and sectors with high concentrations of older people and poor and rural areas and communities of color.

The consequences of racial disparities amount to nearly four years of shorter life expectancy for the average person in the U.S. in 2030, and more than six years for Black people. Of the four demographic groups modeled, Black men and Black women experience the greatest cost in terms of lost years, at 6.6 years and 5.5 years respectively.

An additional 5.9 million survivors would be alive in 2030 (a 1.66 percent difference relative to current baseline projections) - with 92 percent of these among the 50-plus cohort-if

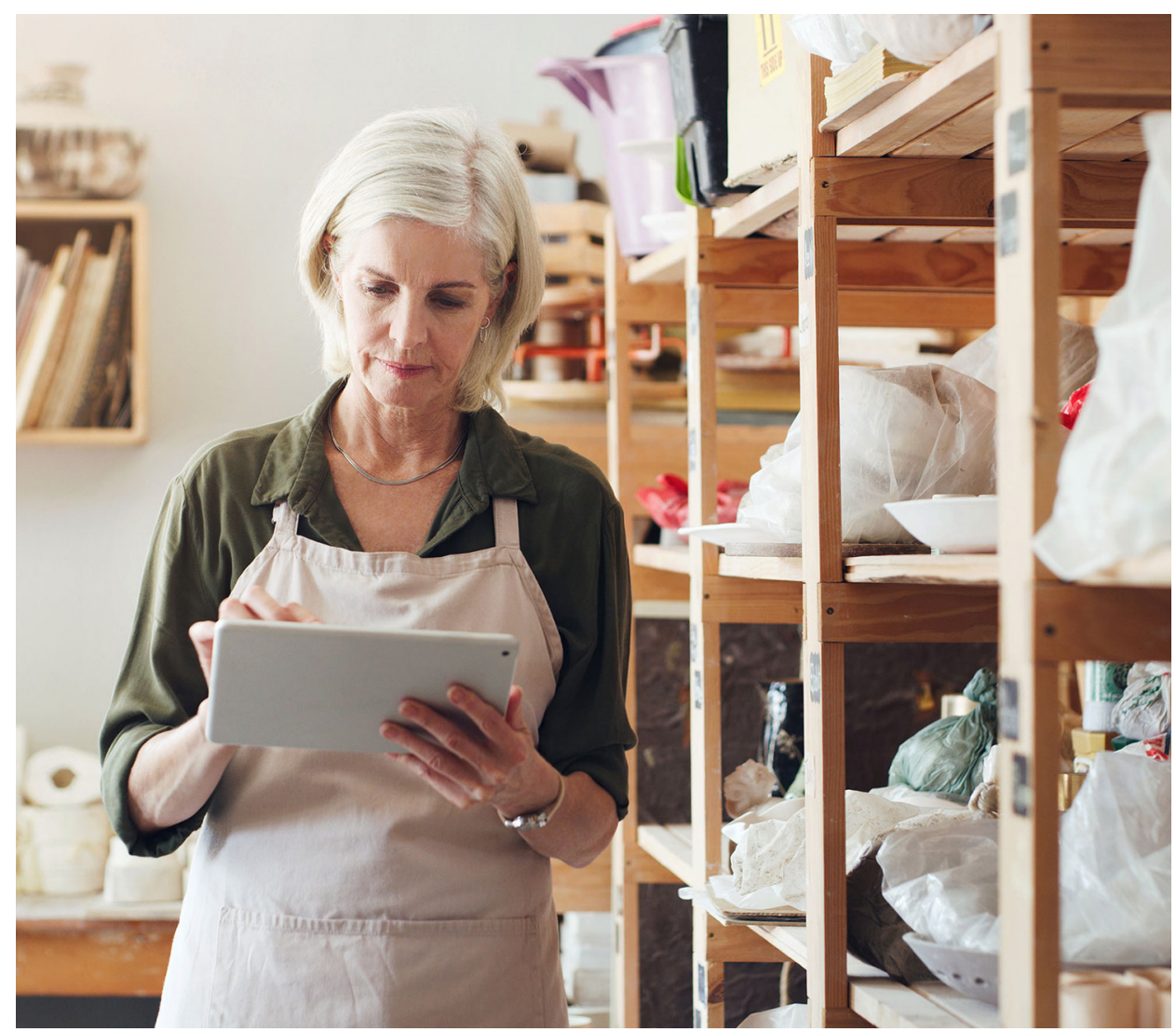

everyone had the same opportunities over the next decade to live longer healthier and more productive lives.

Equalizing racial disparities in life expectancy would raise average U.S. life expectancy in 2030 by $\mathbf{3 . 7}$ years for men and $\mathbf{3 . 8}$ years for women. The effect would be even greater among Black men ( 6.6 years) and Black women (5.5 years).

Many of these costs will be borne by the services, construction, and health sectors, which are most sensitive to population changes. The construction sector's value added to GDP in 2030 would be 12 percent higher under a scenario in which people have an equal chance to live and work longer, driven by the need for new housing and business infrastructure; in the health sector, annual health spending would be $\$ 317$ billion higher in 2030 under an equal scenario, driven by an expanded population.

Achieving longevity equality will require a multisectoral approach that supports the ideal of healthy longevity for all. Achieving healthy longevity as a society will require building the infrastructure to support people of all ages with the opportunity not just live longer but to live longer, healthier, and more productive lives across all of life's stages. This will require an intentional focus on equity as a core strategy to address disparities in everything from education and employment to healthcare and health-related behaviors. 


\section{Disparity in life expectancy in the U.S.}

Life expectancy in the United States varies widely across demographic groups, particularly by race and ethnicity.

White (Non-Hispanic White) people, who make up 60 percent of the U.S. population, ${ }^{2}$ have a life expectancy at birth approximately equal to the national average (78.8 years in 2019). ${ }^{3}$ In contrast, Black/African Americans (Non-Hispanic Black people) in 2019 had a life expectancy at birth that was more than four years lower (74.7 years) than that of White people in the U.S., while Latino/Hispanic people (Hispanic people of all races) in the U.S. could expect to live three years longer than White people., ${ }^{4,5}$ Black people in the U.S. also experience higher-than-average mortality rates at all ages until age 7580. ${ }^{6}$ As we review later in this report, this disadvantage is primarily due to the confluence of several social determinants of health, including structural inequalities in existing laws and institutions.

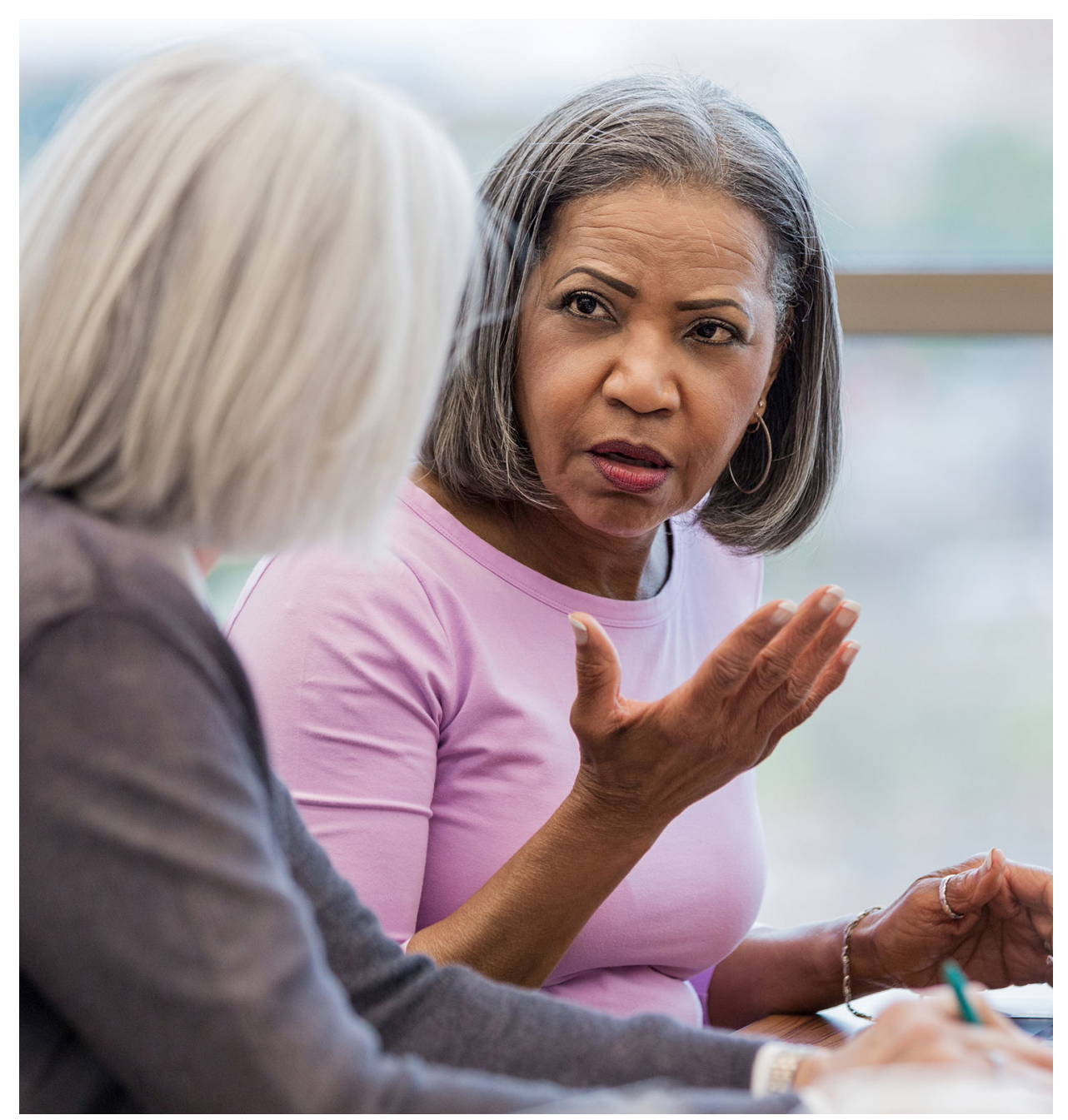

2. Economist Impact, REMI

3. Centers for Disease Control and Prevention, "Provisional Life Expectancy Estimates for 2020." 2021. https://www.cdc.gov/nchs/data/vsrr/VSRR015-508.pdf 4. Ibid.

5. The reasons for higher life expectancy for Latino people in the U.S. are unclear and are sometimes called the "Hispanic Paradox," as Latino life expectancy is higher than expected when accounting for community socioeconomic characteristics. It may to some degree reflect the selection bias of the recent immigrant experiences of many families, with incoming immigrants typically having lower risk factors for mortality, whereas older Latino people in poorer health may migrate back to a home country. (Rogers, R. G., Lawrence, E. M., Hummer, R. A., \& Tilstra, A. M. (2017). Racial/Ethnic Differences in Early-Life Mortality in the United States. Biodemography and social biology, 63(3), 189-205. https://doi.org/10.1080/19485565.2017.1281100) At age 65, both foreign-born men and foreign-born women can expect to live 2.4 years longer than their U.S.-born counterparts. (Mehta, N. K., Elo, I. T., Engelman, M., Lauderdale, D. S., \& Kestenbaum, B. M. (2016). Life Expectancy Among U.S.-born and Foreign-born Older Adults in the United States: Estimates From Linked Social Security and Medicare Data. Demography, 53(4), 1109-1134. https://doi.org/10.1007/s13524-016-0488-4)

6. Roth, D. L., Skarupski, K. A., Crews, D. C., Howard, V. J., \& Locher, J. L. (2016). Distinct age and self-rated health crossover mortality effects for African Americans: Evidence from a national cohort study. Social science \& medicine (1982), 156, 12-20. https://doi.org/10.1016/j.socscimed.2016.03.019 
The disproportionate impact of the COVID-19 pandemic on life expectancy at birth has been dramatic for both Black and Latino people in the U.S. and reflects longstanding structural disparities. In 2020, while White people experienced a decrease of 1.5 years in life expectancy, Black people saw a decrease of 2.9 years and Latino people a decrease of 3.0 years. While the full 2020 life expectancy data is not included in this analysis, these statistics demonstrate that COVID-19 has only heightened the urgency to address the root causes of disparity.

The report focuses on the disparities in longevity between the U.S.'s three largest racial/ethnic groups-Black, Latino, and White people-together with "Other Non-Hispanic" people, which include Asian Americans, Native Americans, Native Hawaiians and Pacific Islanders, multiracial people and all others. The disparities between these categories are significant, and disproportionately affect Black people (see figure 1).
Figure 1

Current disparities in life expectancy disproportionately At age 65 affect Black men and Black women

At age 50

At birth
Women - All

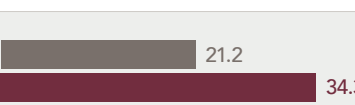

Black

White

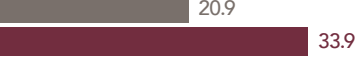

Latino

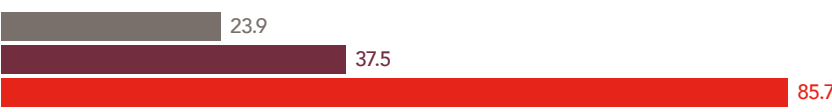

"Other Non-Hispanic"
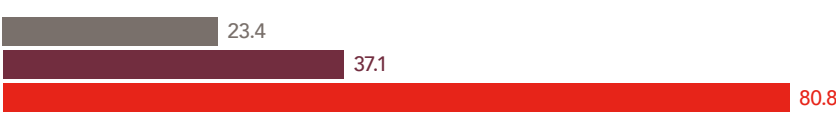

Men - All

18.8

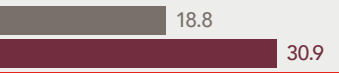

77.6

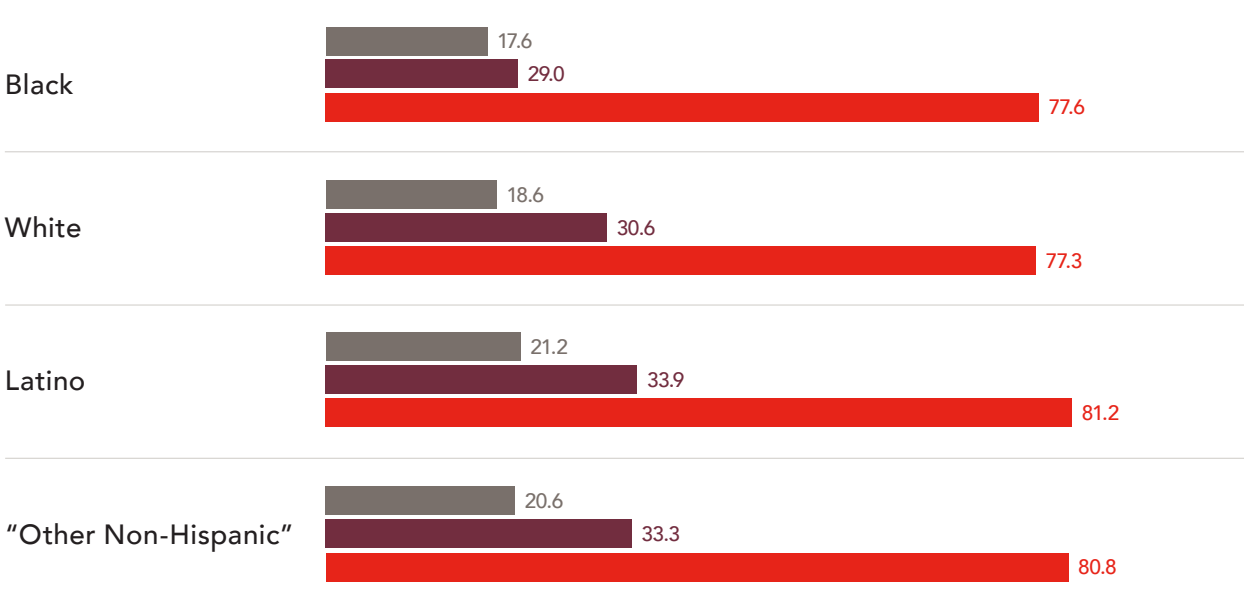

Sources: Economist Impact, REM

Note: Among "Other Non-Hispanics", the U.S. Census has estimated 2015 life expectancy at birth for Asians Americans at 79.9 years (compared to a national average of 79.4), for American Indians and Alaska Natives at 77.5 years, for Native Hawaiians/ Pacific Islanders at 80.1 years, and for those of two or more races at 79.8 years.

7. Centers for Disease Control and Prevention, "Provisional Life Expectancy Estimates for 2020." 2021. https://www.cdc.gov/nchs/data/vsrr/VSRR015-508.pdf

8. U.S. Census. "Projected Life Expectancy at Birth by Sex, Race, and Hispanic Origin for the United States: 2015 to 2060. Table 17." Dec 2014.

https://www2.census.gov/programs-surveys/popproj/tables/2014/2014-summary-tables/np2014-t17.xls 
This report builds on the latest AARP Longevity Economy ${ }^{\circledR}$ Outlook study (see figure 2), which found that the contributions of people 50-plus benefit society and people of all ages. According to the Longevity Economy $®$ Outlook, the annual economic contributions of the 50 -plus age group will triple from $\$ 8.3$ trillion to $\$ 26.8$ trillion by 2050 . However, if there were greater equality in terms of life expectancy in the U.S., these economic projections would be even higher.

The economic contribution of people 50 -plus will be worth $\$ 12.6$ trillion in 2030 . However, if there were greater equality in terms of life expectancy in the U.S., these economic projections would be even higher.

\section{The Longevity Economy ${ }^{\circledR}$ Outlook}

Figure 2

The economic contribution of the 50-plus population will triple by 2050

Contribution of the 50-plus population to U.S. GDP, 2018-50 (\$ trillion)

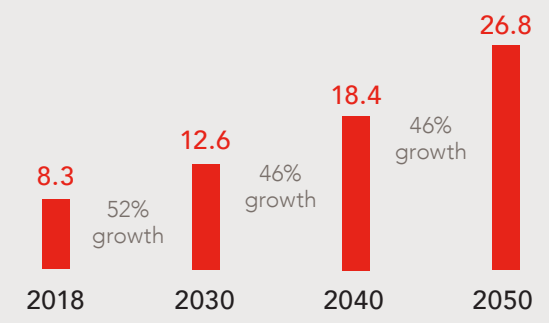

Notes: Nominal GDP.

Sources: The Economist Intelligence Unit,

Bureau of Economic Analysis, REMI.

The Longevity Economy® Outlook, published in 2019, measures the 50plus population's overall contribution to GDP, employment, wages and salaries, and taxes through 2050, and analyzes their unique impact within industries. All forecasts account for the effects of COVID-19 on U.S. demographic and economic projections.

The economic contribution of people 50 -plus will be worth $\$ 12.6$ trillion in 2030; that contribution is forecast to grow to $\$ 26.8$ trillion by 2050 . $^{9}$

In this new report, Our Collective Future: The Economic Impact of Unequal Life Expectancy, we look beyond the overall contribution of the 50-plus population to understand how disparities in life expectancy limit the 50-plus cohort from full participation in the U.S. economy and prevent the realization of additional value, which impacts all of us. ${ }^{10}$

\section{Unequal life expectancy is driven by a variety of socioeconomic}

factors. Previous research has found that socioeconomic characteristics explain much of the difference in life expectancy. ${ }^{11,12}$ In particular, 80 percent of the Black-White life expectancy gap for men, and 70 percent for women, is attributable to demographic and socioeconomic differences-especially income and education, but also employment, occupation, home ownership, urban residence, and marital status. ${ }^{13}$ Research from AARP also suggests that geographical disparities play an important role in life expectancy, impacting people not just at birth, but over the course of a lifetime. ${ }^{14}$ These disparities include unequal access to good schools, clean air, safe cities, healthy food options, and adequate housing and employment opportunities. Finally, structural inequalities are another driver of disparities in life expectancy, which can impact individuals across the socioeconomic spectrum, but may more adversely affect people with fewer resources.

Racial and ethnic disparities in mortality are also high at younger ages. For example, a 2017 study found that Black people experienced 60 percent higher mortality from ages 1 to 24 than NonHispanic White people, and Mexican Americans' mortality risk at those ages was been found to be 32 percent higher than that of Non-Hispanic White people. ${ }^{15}$ The researchers concluded that these disparities were strongly related to differences in parental socioeconomic status and "eliminating socioeconomic gaps across groups is the key to enhanced survival for children and adolescents in racial/ethnic minority groups." 16

\footnotetext{
9. The Longevity Economy® Outlook (2019). https://longevityeconomy.aarp.org/.

10. The Longevity Economy ${ }^{\circledR}$ Outlook takes into account the 50 -plus population's consumption spending, its labor supply, and its tax contributions to estimate this cohort's current economic impact. The life expectancy scenario modeled in the current report estimates the potential economic impact of equalizing life expectancy outcomes across the population.

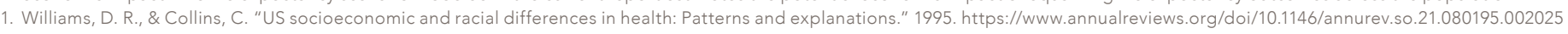

12. Hummer, R. A. "Black-white differences in health and mortality: A review and conceptual model." 1996. https://www.tandfonline.com/doi/abs/10.1111/j.1533-8525.1996.tb02333.x

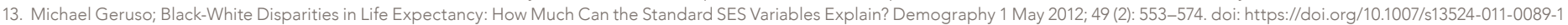

14. Tan, Erwin J. How Growing Geographic and Racial Disparities Inhibit the Ability to Live Longer and Healthier Lives - Report 1: National Level Analysis. Washington, DC: AARP Thought Leadership, October 2020. https://doi.org/10.26419/int.00046.001

15. Rogers, R. G., Lawrence, E. M., Hummer, R. A., \& Tilstra, A. M. (2017). Racial/Ethnic Differences in Early-Life Mortality in the United States. Biodemography and social biology, 63(3), 189-205. https://doi.org/10.1080/19485565.2017.1281100 16. ibid
} 


\section{Disparities in life expectancy} manifest throughout the economy

and labor market. For example, workers who suffer from chronic health issues may be unable to fully participate in the labor force. In addition, workers who perceive themselves to be in worse health may be more likely to retire early, cutting short their lifetime earning potential. Such trends can have a disproportionate impact across the economy, leading to vulnerabilities in sectors that have less favorable demographic and health characteristics.

Black workers, for instance, are more likely to work in the transportation sector, in certain manufacturing sectors such as transportation and appliances, in retail trade (particularly general merchandise stores and online retailers), in telecommunications, and in various service sectors (management, administrative, security, education and health services, accommodation and food services, barber shops, and public administration). ${ }^{17}$ Many of the sectors in which older Black workers are overrepresented could also be described as having "essential workers," who were more adversely affected by the COVID-1918 pandemic and could be more susceptible to future displacement by automation. ${ }^{19}$ Increasing life expectancy, particularly for Black people, would require greater investments in upskilling and reskilling workers across industries and sectors.

\section{Racial disparities in life expectancy have worsened significantly during the COVID-19 pandemic. The Centers} for Disease Control and Prevention (CDC) has estimated that life expectancy in 2020 fell by 1.5 years in the U.S. compared to 2019. The reductions in life expectancy were most stark for Latino and Black people, falling 3.0 years and 2.9 years respectively. These reductions were significantly greater for men than for women (see figure 3). ${ }^{20}$ These unfortunate outcomes are primarily a result of deaths from the coronavirus, but they also reflect a trend of increased mortality at midlife from other causes, including drug overdose, homicide, diabetes, and chronic liver disease, many of which were exacerbated by the pandemic. ${ }^{21}$ These grim updated statistics also demonstrate the potential increased cost-both in lives and dollars - of continued inaction in addressing disparities that have been magnified by the COVID-19 pandemic.
Extensive academic literature highlights the structural inequalities faced by Black and Latino people and Native Americans, which in turn placed them at much greater risk from COVID-19. These structural inequities include a higher prevalence of comorbid conditions and unequal access to education, income, healthcare, and vaccines. ${ }^{22}$ Moreover, COVID-19 is likely to have exacerbated recent trends of rising midlife mortality_as the National Academies of Sciences, Engineering, and Medicine recently noted, these trends are driven by three key causes: alcohol and opioid poisoning, suicide, and cardiometabolic diseases, which are a group of diseases often associated with diabetes, heart disease, and obesity. ${ }^{23}$

\section{Figure 3}

\section{The negative effects of COVID-19 on life expectancy in 2020 were most significant for Black and Latino people-especially men}

\section{Change in life expectancy (years) at birth by race/ethnicity} and gender in the U.S. between 2019 and 2020

Men Women

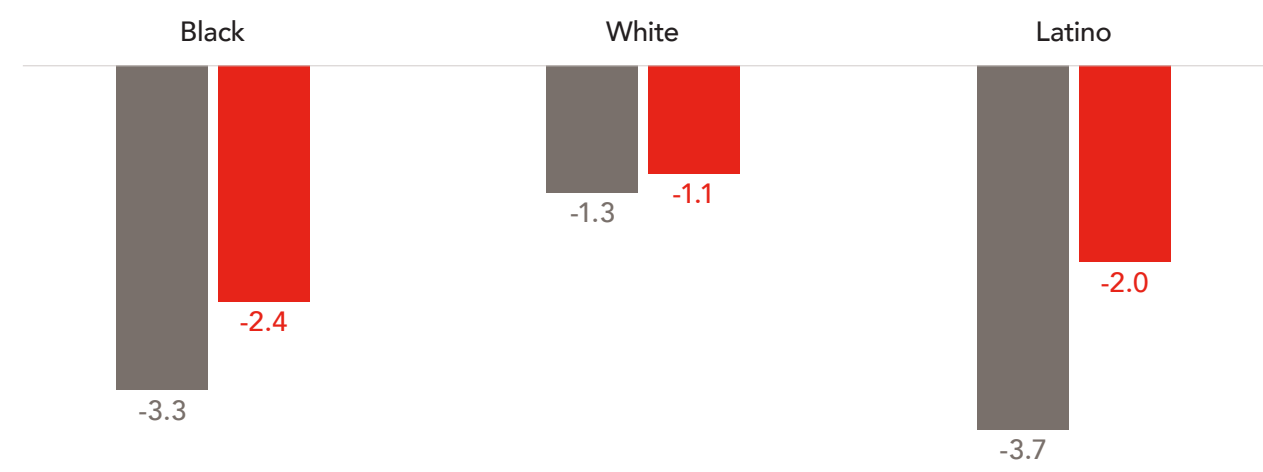

Sources: Centers for Disease Control and Prevention ${ }^{24}$

\footnotetext{
17. Bureau of Labor Statistics. "Labor Force Statistics from the Current Population Survey: Table 18." Accessed June 2021. https://www.bls.gov/cps/cpsaat18.htm

18. Jean Accius, Ramsey Alwin, Erwin Tan, The Intersection of Coronavirus and Racial Inequality in the Workplace, July 24, 2020, Nationswell https://nationswell.com/the-intersection-of-coronavirus-and-racial-inequality-in-the-workplace/

19. Harin Contractor \& Spencer Overton An introduction to Black Workers in the Rural South, Joint Center for Political and Economic Studies January 2020 https://jointcenter.org/wp-content/uploads/2020/02/Intro_To_FoW_In_Black_Rural_South__2-26-20-539pm.pdf

20. Centers for Disease Control and Prevention, "Provisional Life Expectancy Estimates for 2020." 2021. https://www.cdc.gov/nchs/data/vsrr/VSRR015-508.pdf

21. Ibid.

22. Magesh S, John D, Li WT, et al. Disparities in COVID-19 Outcomes by Race, Ethnicity, and Socioeconomic Status: A Systematic Review and Meta-analysis JAMA Netw Open. 2021:4(11):e2134147. doi:10.1001/jamanetworkopen.2021.34147

23. National Academies of Sciences, Engineering, and Medicine 2021. High and Rising Mortality Rates Among Working-Age Adults. Washington, DC: The National Academies Press. https://doi.org/10.17226/25976
} 
The reductions in life expectancy in 2020 caused by COVID-19 translated to an increase of nearly 40 percent in the Black-White life expectancy gap, effectively erasing all progress since 2010. ${ }^{25}$ This precipitous drop for Black people (from 74.7 to 71.8 years ${ }^{26}$ ) reflects how long a person could expect to live if they spent their entire lives under the conditions of 2020.

In addition to the tremendous toll in terms of life expectancy, especially among Black and Latino communities, the economic costs of failing to close these racial gaps repeatedly fall to a great extent on Black people. For example, a recent analysis by the Brookings Institution found that, during the pandemic, Black workers were more likely to be employed in industries hit hardest by the COVID-19 recession and to have fewer savings or other resources. This resulted in a widening of the racial wealth gap, with wealth defined as the difference between a household's assets and debt. Wealth disparities between White and Black households resulted in a greater need among Black people to dip into emergency and retirement savings during the COVID-19 related economic downturn. ${ }^{27}$ Black people, along with Latino people, have also faced the greatest unemployment rates during the pandemic, with lower-wage workers and women aged 50 -plus being especially vulnerable. ${ }^{28}$ One recent analysis suggests that the long-term impact of the COVID-19 unemployment shock could translate to an additional 800,000 deaths over the next 15 years, with a disproportionate impact on Black Americans and women. ${ }^{29}$

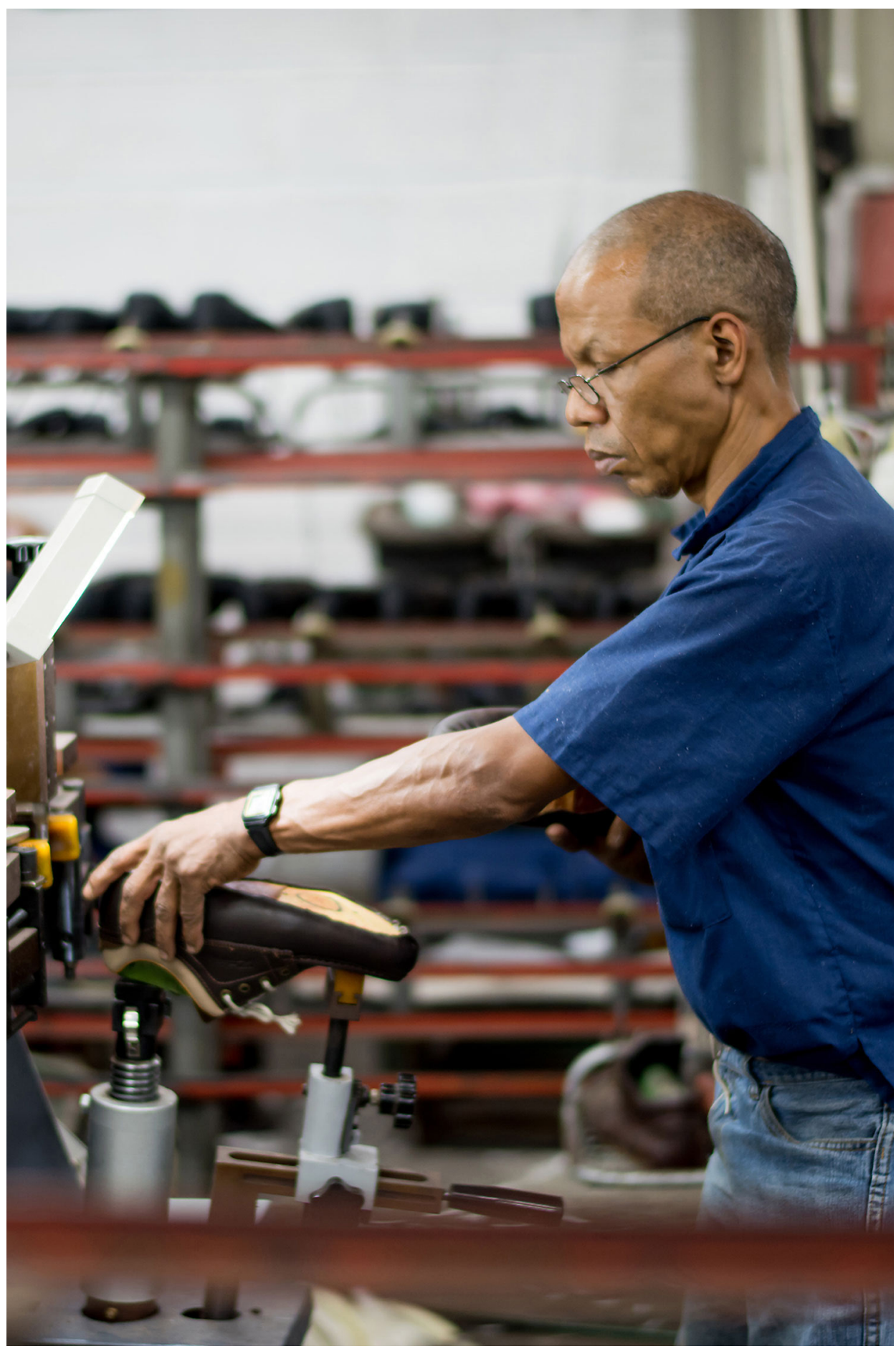

24. Centers for Disease Control and Prevention, "Provisional Life Expectancy Estimates for 2020." 2021. https://www.cdc.gov/nchs/data/vsrr/VSRR015-508.pdf

25. Theresa Andrasfay, Noreen Goldman Reductions in 2020 US life expectancy due to COVID-19 and the disproportionate impact on the Black and Latino populations Proceedings of the National Academy of Sciences Feb 2021, 118 (5) e2014746118; DOI: 10.1073/pnas.2014746118

26. Centers for Disease Control and Prevention, "Provisional Life Expectancy Estimates for 2020." 2021. https://www.cdc.gov/nchs/data/vsrr/VSRR015-508.pdf

27. Emily Moss, Kriston Mclntosh, Wendy Edelberg, and Kristen Broady, The Black-white wealth gap left Black households more vulnerable December 8 , 2020, https://www.brookings.edu/blog/up-front/2020/12/08/the-black-white-wealth-gap-left-black-households-more-vulnerable/

28. Congressional Research Service. "Unemployment Rates During the COVID-19 Pandemic" Accessed June 2021. https://fas.org/sgp/crs/misc/R46554.pdf

29. Francesco Bianchi, Giada Bianchi, and Dongho Song, The Long-Term Impact of the COVID-19 Unemployment Shock on Life Expectancy and Mortality Rates, NBER Working Paper No. 28304, December 2020, Revised September 2021 JEL No. C32,E32,114,J11 


\section{The economic cost of racial disparities in life expectancy}

This study considers the question: What is the economic cost to the U.S. of current disparities in life expectancy across demographic groups?

To estimate this, the study utilizes a counterfactual scenario in which the U.S. experiences a decade (2022-2030) with no disparities in life expectancy across races/ethnicities (i.e., a world with full equality). By comparing this scenario's outcomes against our baseline scenario (no changes to current expectations), we are able to estimate the broader economic costs imposed on society by unequal life expectancy. This study provides a baseline for understanding these costs-however, the true cost of racial and ethnic inequality (encompassing disparities in education and job discrimination) is likely much greater.

The annual economic cost to the U.S. caused by unequal life expectancy is projected to reach $\$ 1.6$ trillion by 2030

(see figure 4), a figure equivalent to the combined size of Massachusetts' and Virginia's economies in 2030. The cost of these disparities also manifests across the labor market, taking a toll to the tune of 10.1 million jobs and $\$ 934$ billion in wages and salaries in 2030 (see figures 5 and 6). This cost disproportionately falls on workers aged 50-plus, who account for 77 percent of labor force participants that would otherwise be able to remain active in the workforce longer (if life expectancies were equal).
Figure 4

Disparities in life expectancy are projected to cost the U.S. \$1.6 trillion in 2030 (5.1 percent of projected GDP)

Annual cost to U.S. GDP in 2030 resulting from disparities in life expectancy

\section{$\$ 1.6$ trillion}

Projected 2030 GDP of...

Massachusetts: $\$ 0.82$ trillion

Virginia: $\$ 0.78$ trillion

Figure 5

The annual economic cost of disparities would reach 10.1 million jobs in 2030 (4.9 percent of the total)

Annual cost to U.S. jobs in 2030 resulting from disparities in life expectancy

10.1 million

U.S. decline in employment during the Great Recession

8.6 million

Figure 6

Disparities in life expectancy would cost the U.S. \$934 billion in wages and salaries in 2030 (4.9 percent of the total)

Annual cost to U.S. wages and salaries in 2030 resulting from disparities in life expectancy

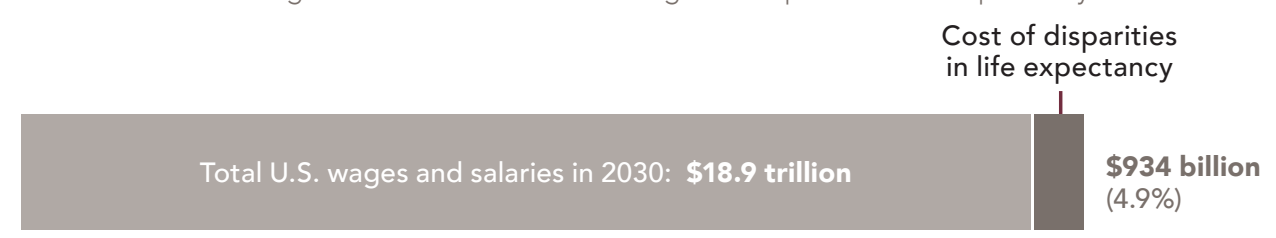

Note: All total costs are estimated relative to the potential economic outcomes observed under the 'counterfactual scenario,' which features full equality of life expectancy.

Sources: Economist Impact, REMI 
The consequences of racial disparities amount to nearly four years of shorter life expectancy for the average person in the U.S., and more than six years for Black people. Of the four demographic groups modeled, Black men and Black women experience the greatest cost in terms of lost years, at 6.6 years and 5.5 years respectively (see figure 7 ). The costs to longevity remain large when

Figure 7

\section{Equalizing racial disparities in life expectancy would} raise average U.S. life expectancy in 2030 by 3.7 years for men and 3.8 years for women

Potential impact on life expectancy (years) in 2030, if racial disparities did not exist

At birth

At age 50
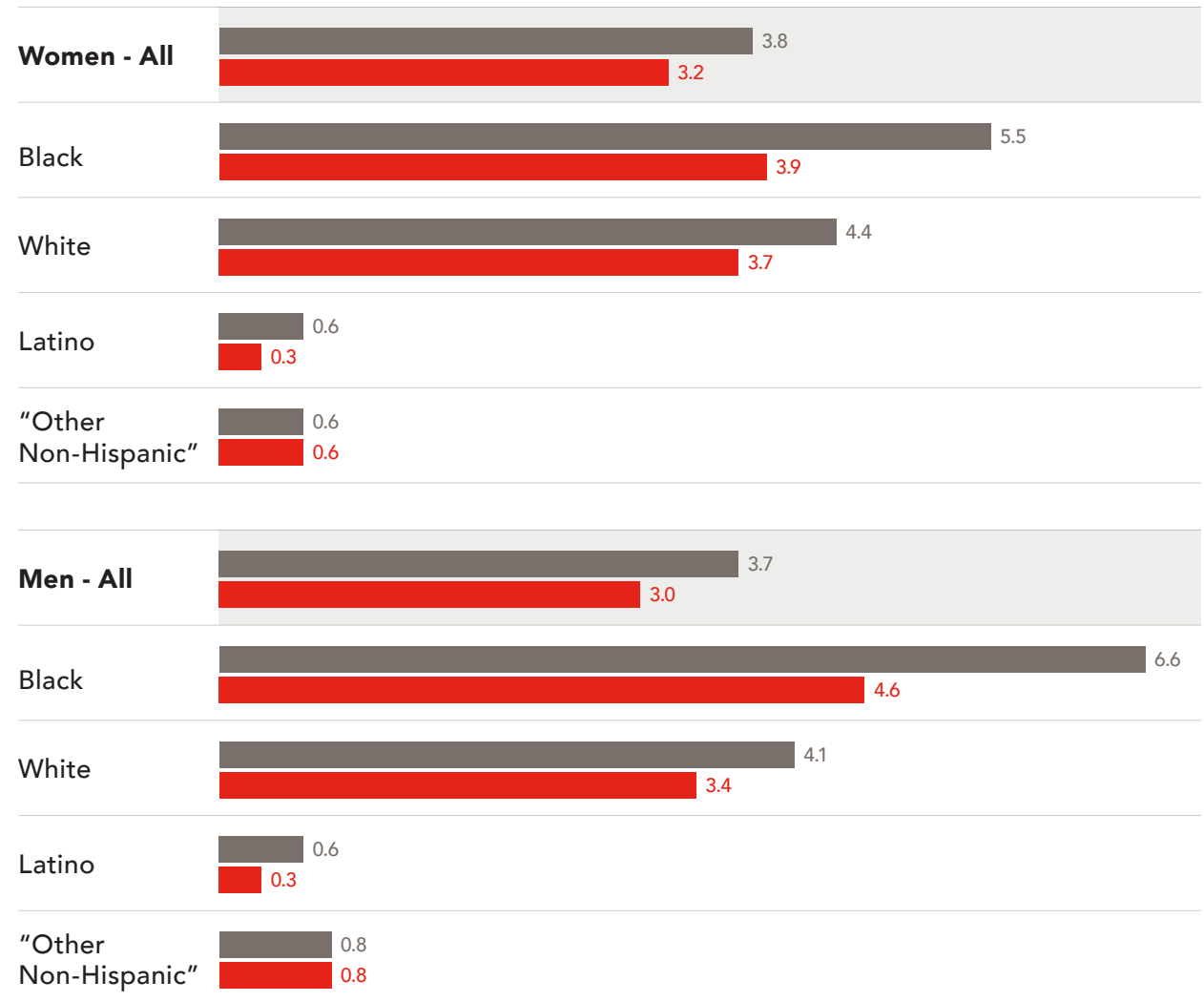

Note: If Native Americans had been included in the model, they would have had the largest potential impact in terms of life expectancy. Native Americans are instead included under people of other Non-Hispanic race due to limitations in the data. Sources: Economist Impact, REMI

\section{How we did it:}

Notes on the methodology

The analysis treats the life expectancy of each gender separately. Four racial/ethnic groups were used in the data modeling: Black people (Non-Hispanic Black people), White people (Non-Hispanic White People), and Latino people (Hispanic people of all races), together with a fourth group referred to as "Other NonHispanic" people. The final group encompasses Asian Americans, Native Americans, Native Hawaiians and Pacific Islanders, multiracial people, and all others. These subgroups were not included as separate categories in this analysis because of limitations in the data and models used.

The counterfactual scenario assumes that each of four groups would have an equally high level of life expectancy. This ideal or aspirational level/age is defined as the number of years a person could expect to live if-during each year of life-that person had the same mortality risk as the best-performing demographic group at each age.

The scenario was constructed using the REMI PI+ model. This model relies on demographic data from sources such as the U.S. Census, Centers for Disease Control and Prevention, the Bureau of Labor Statistics, and others.

For further details about the methodology, see Appendix 1. 
In addition to these impacts on life expectancy, racial disparities entail costs in terms of "healthspan"—-the ability of individuals to live simultaneously healthier and longer lives, rather than simply living longer but in poor health. Research has long revealed that Black people rate their health worse ${ }^{30}$ and are more likely to live a greater proportion of life with a disability or serious disease. ${ }^{31,32,33,34}$ Scholars have also shown that communities with health disparities face a host of structural inequities challenging their ability to age in good health, including exposure to environmental hazards, poverty, and limited access to medical care. ${ }^{35}$
The costs of disparity in life expectancy affect all of us. In our counterfactual scenario with full equality of life expectancy, the U.S. would accumulate 5.9 million additional survivors by 2030-92 percent of whom would be members of the 50-plus cohort (see figure 8). This number highlights just how substantial the cost of unequal life expectancy is for older people. (The impact is concentrated among older people because the gap between the best and worst mortality rates is much greater at older ages.) Of the 5.9 million more people who would be alive under the counterfactual scenario, White and Black people would see the greatest boost to their populations relative to their baseline population sizes.
The effects of unequal life expectancy can impact all of us, not only the communities that experience these disparities directly. The impact of disparities on life expectancy is reflected in research by demographers who have noted that, historically, increases in life expectancy have been accompanied by increases in lifespan equality: "As people live longer, ages at death are becoming more similar." ${ }^{36}$ Individuals should consider that their own life expectancy might be tied to the life expectancy of their neighbors who are experiencing disparities.

Figure 8

If life expectancy from 2022 to 2030 were equalized across demographic groups, the U.S. population in 2030 would be 5.9 million higher than its baseline projection (a 1.66 percent difference)

Age breakdown of additional survivors in 2030 (\%) by cohort, after a decade without disparities in longevity between demographic groups

75-plus

ㅁ. 65-74

- 50-64

- 16-49

- Under 16

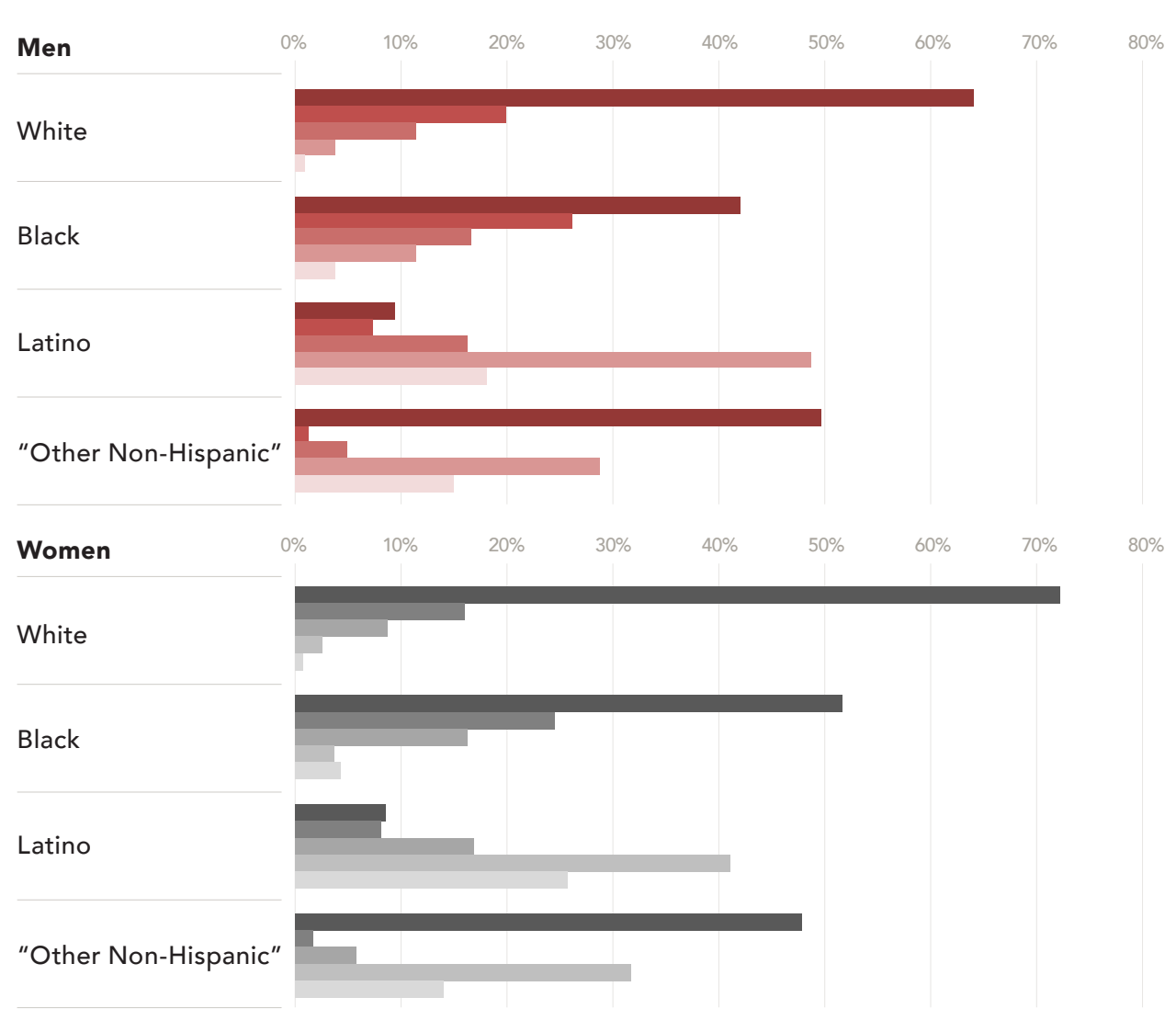

30. Farmer MM, Ferraro KF. Are racial disparities in health conditional on socioeconomic status? Soc Sci Med. 2005 Jan;60(1):191-204. doi: 10.1016/j.socscimed.2004.04.026. PMID: 15482878.

31. Hayward MD, Heron M. Racial inequality in active life among adult Americans. Demography. 1999 Feb:36(1):77-91. PMID: 10036594.

32. National Center for Health Statistics (US). Health, United States, 2015: With Special Feature on Racial and Ethnic Health Disparities. Hyattsville (MD): National Center for Health Statistics (US); 2016 May. Report No.: 2016-1232. PMID: 27308685.

33. Siegel RL, Miller KD, Jemal A. Cancer statistics, 2016. CA Cancer J Clin. 2016 Jan-Feb;66(1):7-30. doi: 10.3322/caac.21332. Epub 2016 Jan 7. PMID: 26742998.

34. Sorlie PD, Backlund E, Keller JB. US mortality by economic, demographic, and social characteristics: the National Longitudinal Mortality Study. Am J Public Health. 1995 Jul;85(7):949-56. doi: 10.2105/ajph.85.7.949. PMID: 7604919; PMCID: PMC1615544.

35. Kenneth F Ferraro, PhD, Blakelee R Kemp, MA, Monica M Williams, MA, Diverse Aging and Health Inequality by Race and Ethnicity, Innovation in Aging, Volume 1, Issue 1, 1 March 2017, igx002, https://doi.org/10.1093/geroni/igx002

36. Bergeron-Boucher, Marie-Pier, Villavicencio, Francisco, Tan, Erwin J., Vaupel, James W., 2020. "Longevity and Equity" AARP International: The Journal, vol.13: 26-29. https://doi.org/10.26419/int.00045.014 


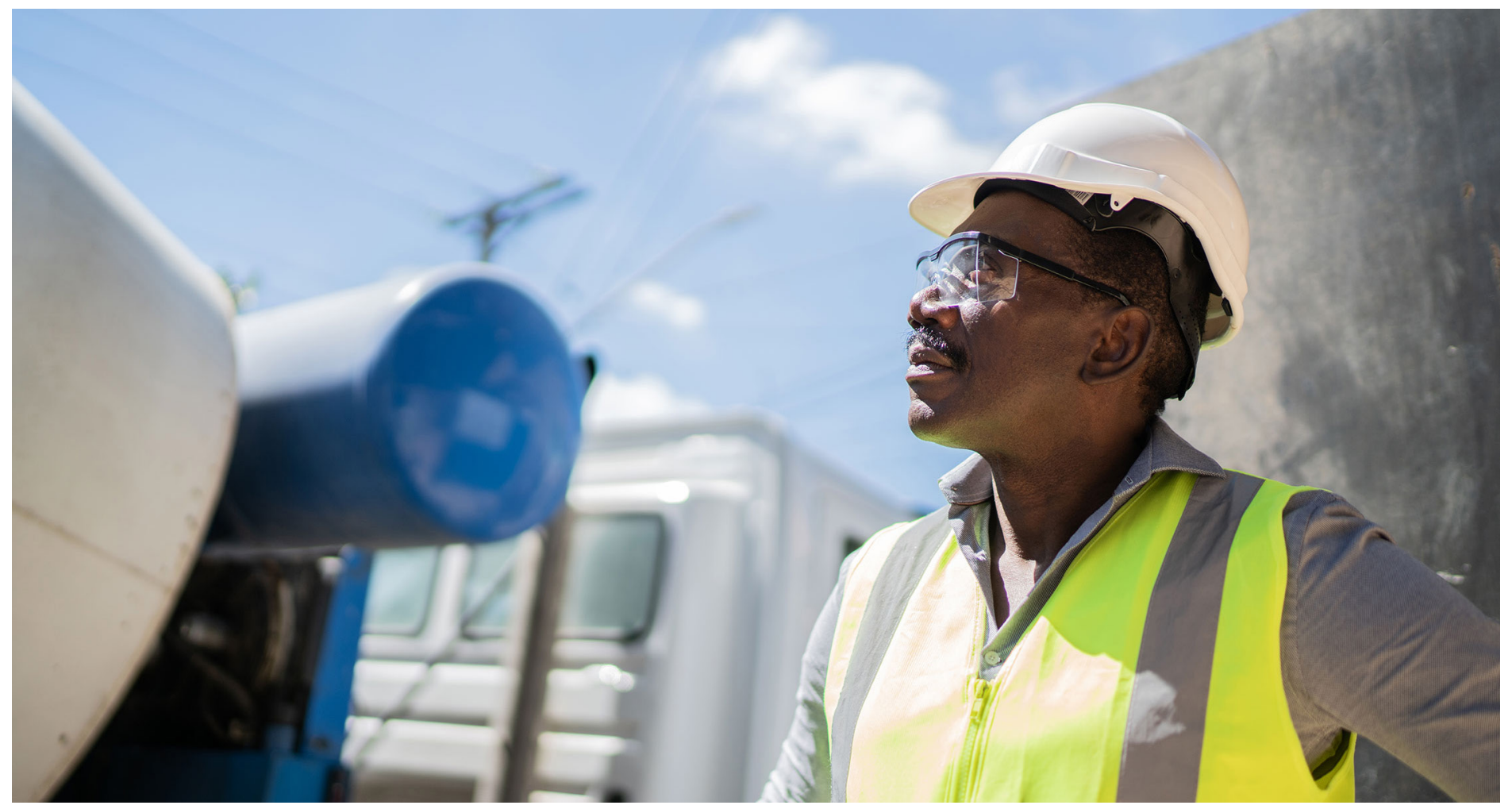

The services, health, and construction sectors experience the greatest costs from unequal life expectancy. The construction sector faces the most pronounced costs from unequal life expectancy-12 percent in value added (see figure 9)-with lower levels of new housing and business infrastructure investment when compared to the counterfactual scenario in which people would live and work longer. While the construction sector is somewhat of an outlier, due to its unique dependence on population growth, other sectors also face similar consequences from a smaller population. This includes many service industries (especially health, education, finance, and other servicesall facing costs above 5 percent of their baselines), wholesale and retail trade (5.5 percent), and technology (5.8 percent).

Figure 9

Disparities in life expectancy represent a significant cost to industries such as construction, services, and health, which are highly sensitive to the size of the population

Annual cost to industry GDP in 2030 from disparities in life expectancy

Construction

Other services

Health services

Technology

Wholesale and retail trade

Education services

Finance, insurance, and real estate

Transportation

Information

Leisure and hospitality

Automotive manufacturing

Professional and business services

Manufacturing

Utilities

Government

Natural resources, mining, and farming

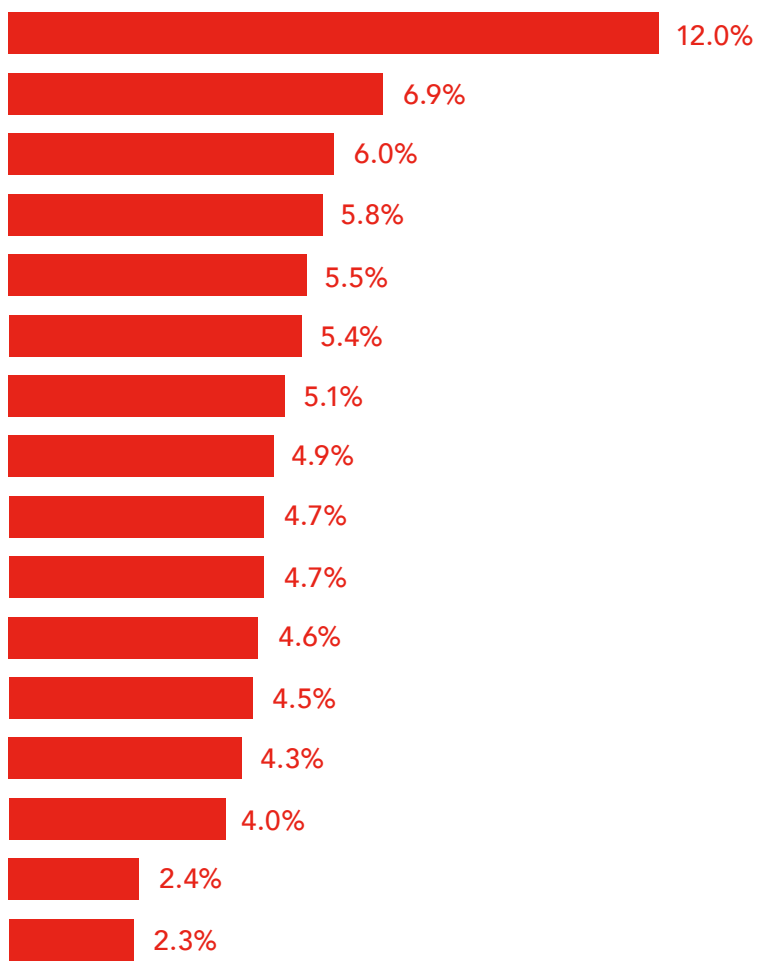


Consumer spending is also negatively affected by disparities in life expectancy (see figure 10). The annual loss in total spending (compared to the equal scenario) will reach nearly $\$ 1.1$ trillion in 2030. Impacts would be felt most for products commonly purchased by older people, including financial services and insurance (8.0 percent of its baseline level in 2030), heath care (6.5 percent), motor vehicles (5.9 percent), transportation services (7.4 percent), and technology (7.1 percent). For some products, such as health spending, these impacts on total spending are primarily due to differences in population size, rather than changes in per capita health costs.
Figure 10

Disparities in life expectancy are projected to negatively impact total consumer spending in 2030 by 5.3 percent

Annual cost to consumer spending in 2030, by product category, relative to baseline levels

Financial services \& insurance

Transportation services

Technology

Health care

Motor vehicles and parts

Other durable goods

Leisure and hospitality

\section{All commodities}

Other services

Clothing and footwear

Other non-durable goods

Education services

Groceries

Housing and utilities

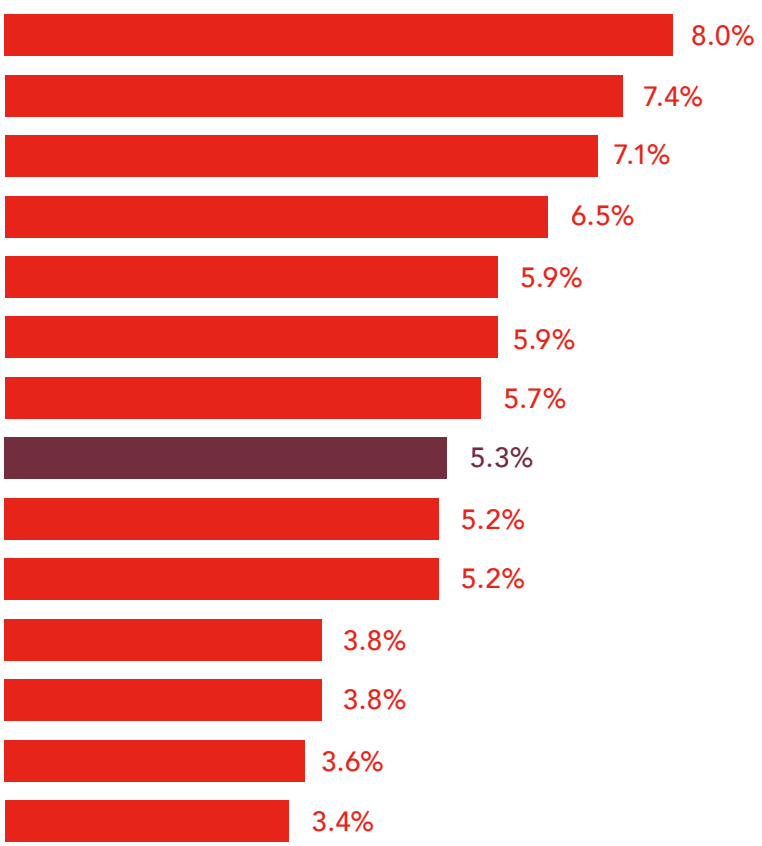

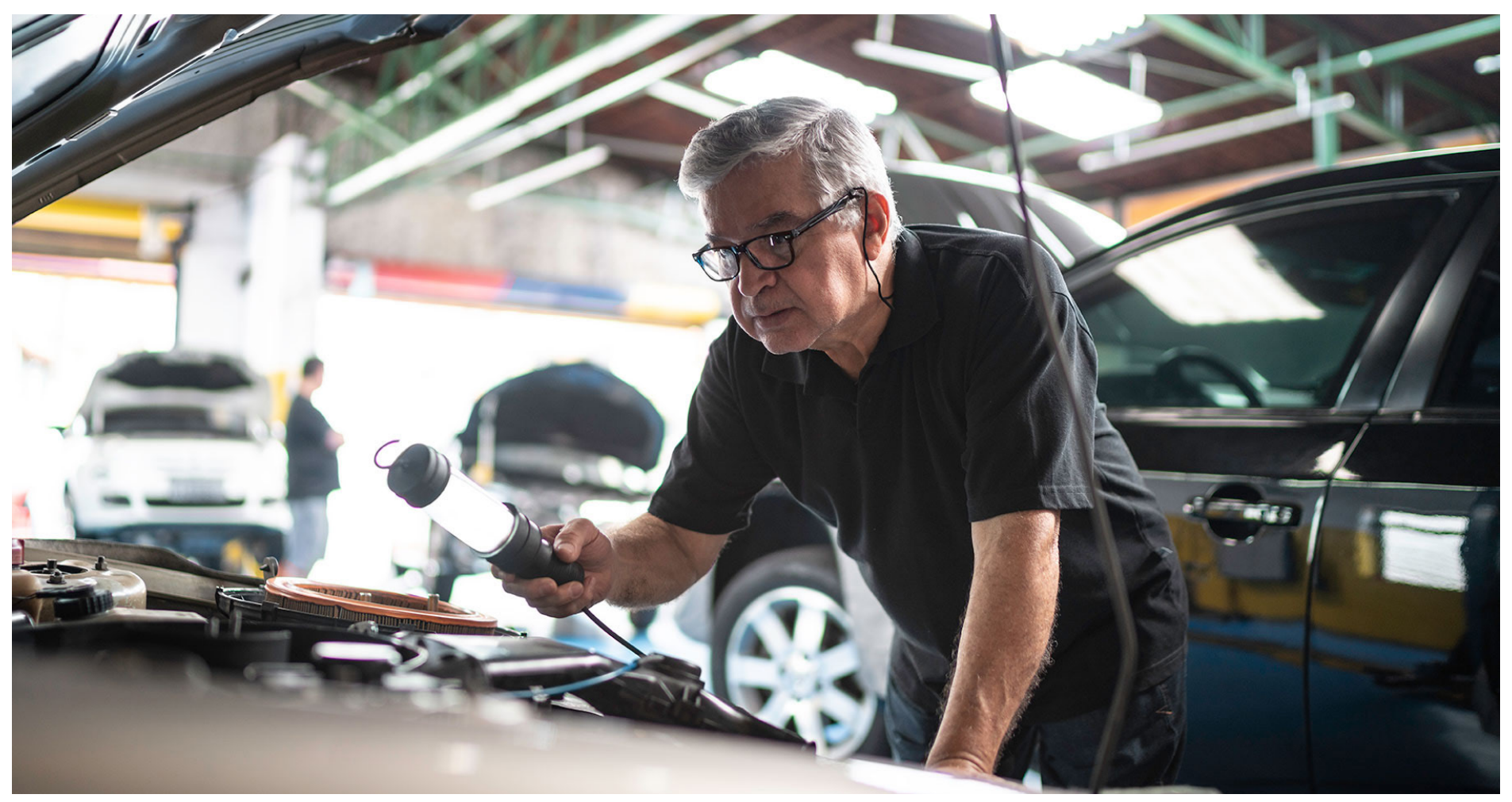




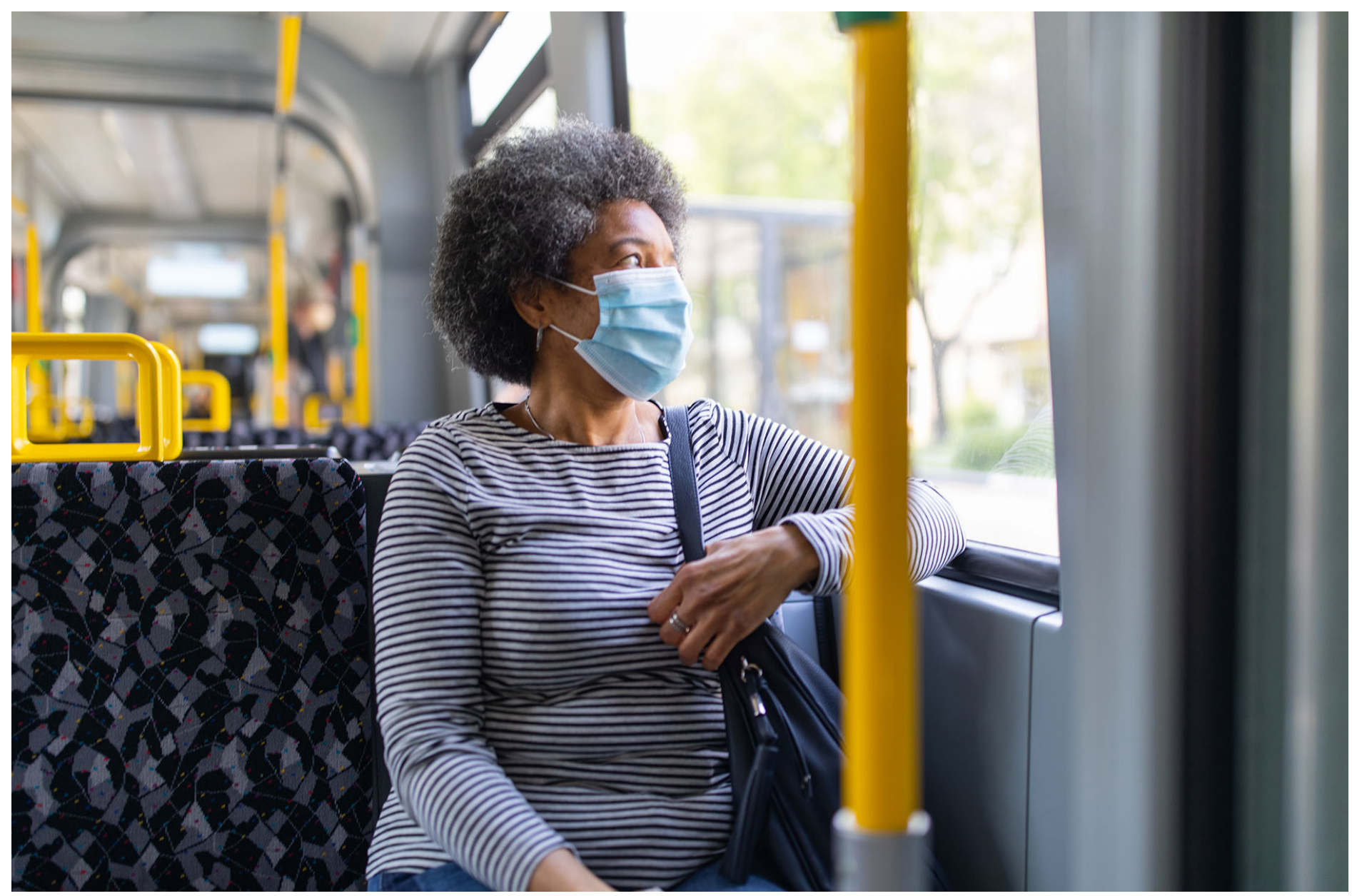

The costs of unequal life expectancy are not equally distributed across the country or the economy. These negative effects hit some groups and regions much harder than others-in particular, regions and sectors with high concentrations of older people and poor and rural areas and communities of color.

As a recent AARP study emphasized, where you are born matters. Since 1980, the gap in life expectancy disparities between the best-performing and worst-performing counties in the U.S. has worsened. That gap has widened even further when measured using life expectancy at age 50, demonstrating that where a person lives has a direct impact on life expectancy throughout one's life and not just at birth. ${ }^{37}$
The costs of disparity in life expectancy also manifest in varied ways across the economy, including in the products and services that people can access. For example, spending on health and leisure suffers some of the largest consequences from unequal life expectancy in our study (6.5 percent and 5.7 percent of their baseline levels, respectively). While much of this effect is because older adults tend to spend more on these types of items, it is also important to emphasize that unequal access to healthrelated goods and healthy lifestyles is a major issue. Similarly, problems of unequal access to healthy food options, health care, and other lifestyle benefits are well documented in poor and rural areas and communities of color. ${ }^{38,39}$ 


\section{Closing the racial gap in life expectancy}

Closing the disparities in life expectancy requires action on many fronts-but as this research shows, the financial costs of inaction are immense and impact everyone.

As long as these disparities persist, the costs will continue to rise and compound. This report seeks to inspire action toward achieving equity by providing an extensive estimate of the economic benefit of progress in closing these disparities. Such benefits include increased opportunities to work, greater economic activity, and boosts to consumers spending, which are amplified by other individual and community benefits.

The continued cumulative costs of inaction are unsustainable. Achieving the vision of healthy longevity will require a multisectoral approach whereby everyone has a responsibility to support the ideal of healthy longevity for all. Healthy longevity is a characteristic of societies where people live longer with good health and wellbeing. They achieve equality in both life expectancy and "healthspan" (the period of life in good health), and the individuals are empowered to live their best and healthiest lives. This will require building a robust infrastructure to ensure that people of all ages have the opportunity to live longer, healthier, and more productive lives.
The connection between an individual's healthspan and lifespan is reflected in research by demographers who have noted how increases in life expectancy have historically been accompanied by increases in lifespan equity." ${ }^{40}$ As we address racial and ethnic inequality and rebuild our society to be more equitable and healthier across the lifespan, progress in overall life expectancy should follow. Therefore, investments in increasing life expectancy should focus equally on increasing equity. However, recently published CDC reports about widening disparities in life expectancy in 2020 show that the road to equality will not be immediate or easy.

These trends demonstrate the need for increased attention and resources, and this report provides additional economic justification for urgent action. To this end, there are important steps we can take right now to ensure quicker progress toward equality:

\section{We need better data on health outcomes by race and ethnicity.}

Addressing disparities requires better data at the state and local level to be collected by public health departments and heath care systems. There is longstanding need for better health system data relating to disparities. The pandemic exposed and magnified gaps in public reporting of COVID-19 data by race and ethnicity with consistent patterns of incomplete information, missing data, and inconsistencies in labeling racial and ethnic groups. ${ }^{41}$ The impact of a lack of data by race and ethnicity will only grow as the U.S. becomes increasingly diverse. For example, the 2020 Census showed that Asian Americans are the fastest growing of the nation's four largest racial and ethnic groups. However, the Census also showed a great deal of socioeconomic diversity among Asian American communities, with greater disparities for many Asian American communities from specific countries of origin. ${ }^{42}$

\section{Long-term strategies for improving life} expectancy need to center on reducing income and education inequalities. As

previous research has demonstrated, these two socioeconomic characteristics explain the vast majority of differences in life expectancy. ${ }^{43}$ Stronger employment policies to ensure equal pay are vital for combating income inequality and fostering better health throughout life. Central to this is improving access to education across the life course - this will entail addressing the U.S. education system's twin problems of racial inequality and wealth inequality. With more jobs than ever requiring higher skills and education levels, addressing education disparities is vital to addressing disparities in career outcomes and incomes. Many older adults have unfulfilled dreams of completing their education. Barriers to education earlier in life among older Black American and Latino populations especially have left a lasting legacy of disparities in educational attainment.

\footnotetext{
40. Bergeron-Boucher, Marie-Pier, Villavicencio, Francisco, Tan, Erwin J., Vaupel, James W., 2020. "Longevity and Equity" AARP International: The Journal, vol.13: 26-29. https://doi.org/10.26419/int.00045.014

41. Beth Carter, Edem Hado, Using Data to Disrupt Health Disparities: Lessons Learned from the Coronavirus Pandemic https://blog.aarp.org/thinking-policy/using-data-to-disrupt-health-disparities-lessons-learned-from-the-coronavirus-pandemic

42. Robert Gebeloff, Denise Lu and Miriam Jordan Inside the Diverse and Growing Asian Population in the U.S. Aug. 21, 2021, https://www.nytimes.com/interactive/2021/08/21/us/asians-census-us.html

43. Michael Geruso; Black-White Disparities in Life Expectancy: How Much Can the Standard SES Variables Explain? Demography 1 May $2012 ; 49$ (2): $553-574$. doi: https://doi.org/10.1007/s13524-011-0089-1
} 
Improving access to health care and preventative care for underserved populations can have direct and indirect impacts on life expectancy. This includes continuing to support policies that expand access to affordable health insurance and Medicaid and improve delivery of health services in poor communities and communities of color. Such actions can prevent many premature deaths, which occur much more frequently among individuals without good access to health care, ${ }^{44,45}$ and would be instrumental in improving health outcomes for both the young and the old. Among workingage adults, better health access would help combat the rise in drug- and alcohol-related deaths, suicides, and cardiovascular disease, while, for older Americans, it would improve long-term/ chronic health outcomes. ${ }^{46}$ A more comprehensive safety net for low-income individuals (and especially children) would allow for better access to healthy lifestyles, preventative care, and other important resources that are too often out of reach for many Americans.

\section{We must build equitable systems that ensure everyone has the means to match their aspirations in health and life.}

Governments and businesses can also take steps to improve geographic disparities in life expectancy by addressing social determinants of health. Communities should be livable and all residents in all neighborhoods deserve the same number of years to grow old with their families; play with their friends; enjoy books, movies and music; and watch their grandchildren grow up. Businesses and municipal governments can work together to ensure zoning regulations and city development plans promote equal access to good quality food, recreation, social connection, and other healthy consumer options for older residents and communities of color.
We must build equitable systems that ensure everyone has the means to match their aspirations in health and

life. We all have a responsibility to pursue systemic change by examining current policies and practices that, intentionally or not, create barriers to access, resources, opportunities, and empowerment, leading to inequities and obstructing health security and financial resilience. Communities should seek to conduct comprehensive audits to ensure that policies, practices, programs and services are not perpetuating structural inequities.

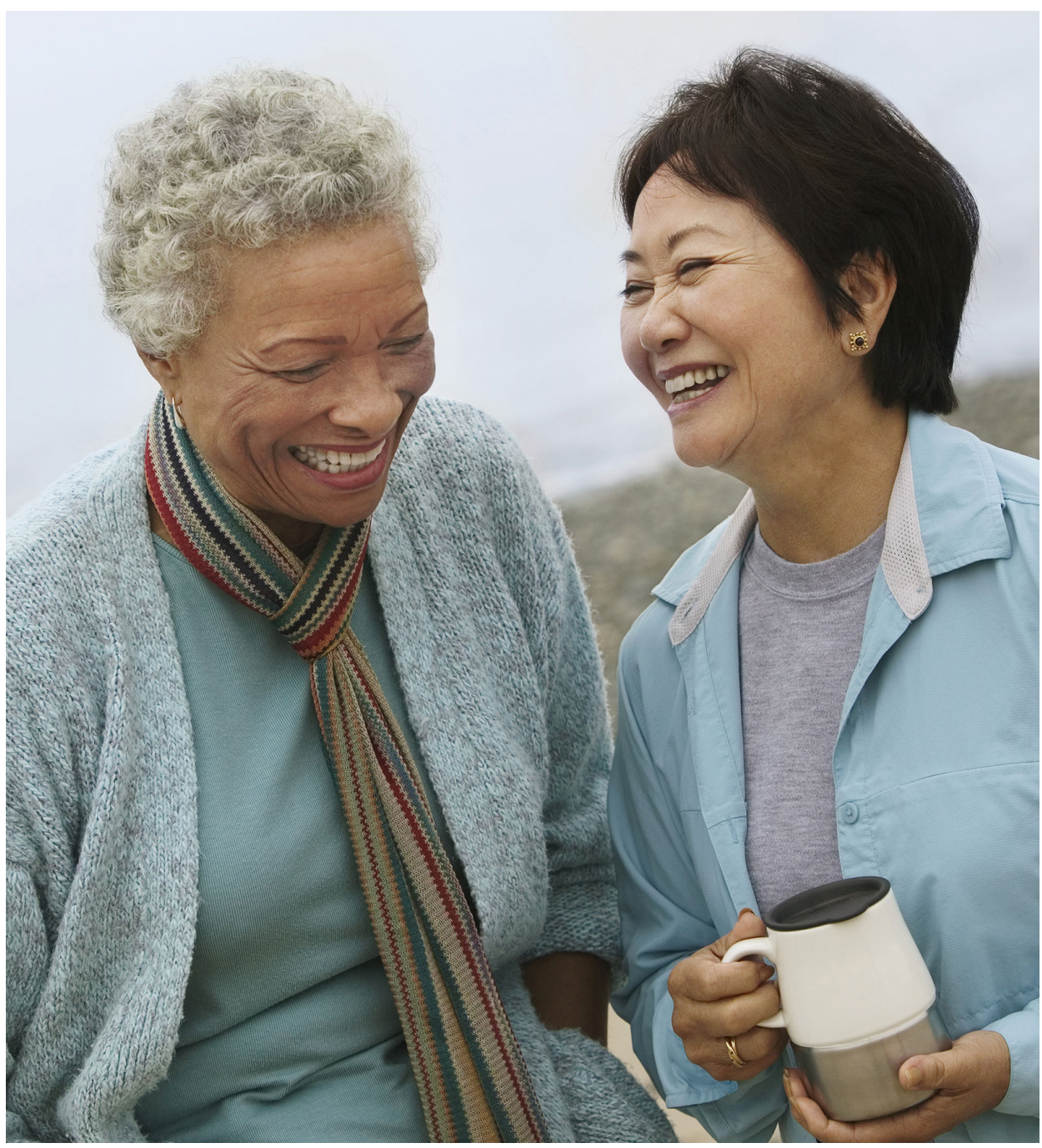

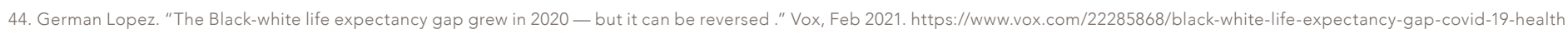

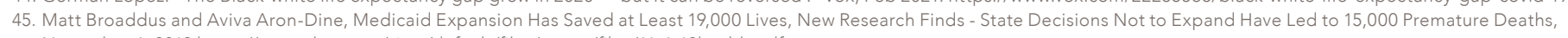
November 6, 2019 https://www.cbpp.org/sites/default/files/atoms/files/11-6-19health.pdf

46. National Academies of Sciences, Engineering, and Medicine 2021. High and Rising Mortality Rates Among Working-Age Adults. Washington, DC: The NationalAcademies Press. https://doi.org/10.17226/25976. 


\section{Final Thoughts}

The moral and economic costs of disparities in life expectancy highlight the importance of engaging many stakeholders to close the longevity gap.

Among the strategies experts consider most important for making longevity more equitable is the necessity for collaboration between the private and nonprofit sectors to create multistakeholder solutions. Furthermore, these solutions should be designed with the needs of those at the margins, and not exclusively those in the middle, in mind. ${ }^{47}$ An important first step will be to recognize and engage communities affected by these disparities in longevity.

As this report underscores, we cannot afford to live in a post-COVID-19 America where disparities and disadvantages only grow deeper and wider as we age. The 2020 Census shows that over the last 10 years, people who identified as Latino, Asian, or more than one race accounted for increasing shares of the population, and that this diversity is rising in almost every county. ${ }^{48}$ As the United States continues to become more diverse, a prosperous future will require a more equitable future, where prosperity is sustainable for all. As shown in this report, such improvements in life expectancy have the potential to generate a myriad of broad-based economic benefits for all, helping to close these gaps even further as part of a "virtuous cycle." Now, more than ever, we need bold solutions and ideas to ensure a society that equitably supports heathy longevity.

We need to build new systems and infrastructures that value equity, opportunity, and interdependence as a means to success. We have an opportunity to construct a future that strengthens health and builds wealth through increased healthy longevity and equity-but we must start now. A society that supports healthy longevity and improved healthspans also supports the 50-plus cohort as they contribute to communities and fuel economic growth well past the traditional retirement age. We must act because closing the longevity gap could generate an additional $\$ 1.6$ trillion to our GDP in 2030. Ensuring that everyone has equitable opportunities to achieve their fullest potential means that all of society, including business and government, will benefit. The additional revenue from equitable life expectancy could be reinvested in society to support a range of national priorities. We are at a juncture where we must respond to the fierce urgency of now. The economic cost of continued inaction is unsustainable for our collective growth.

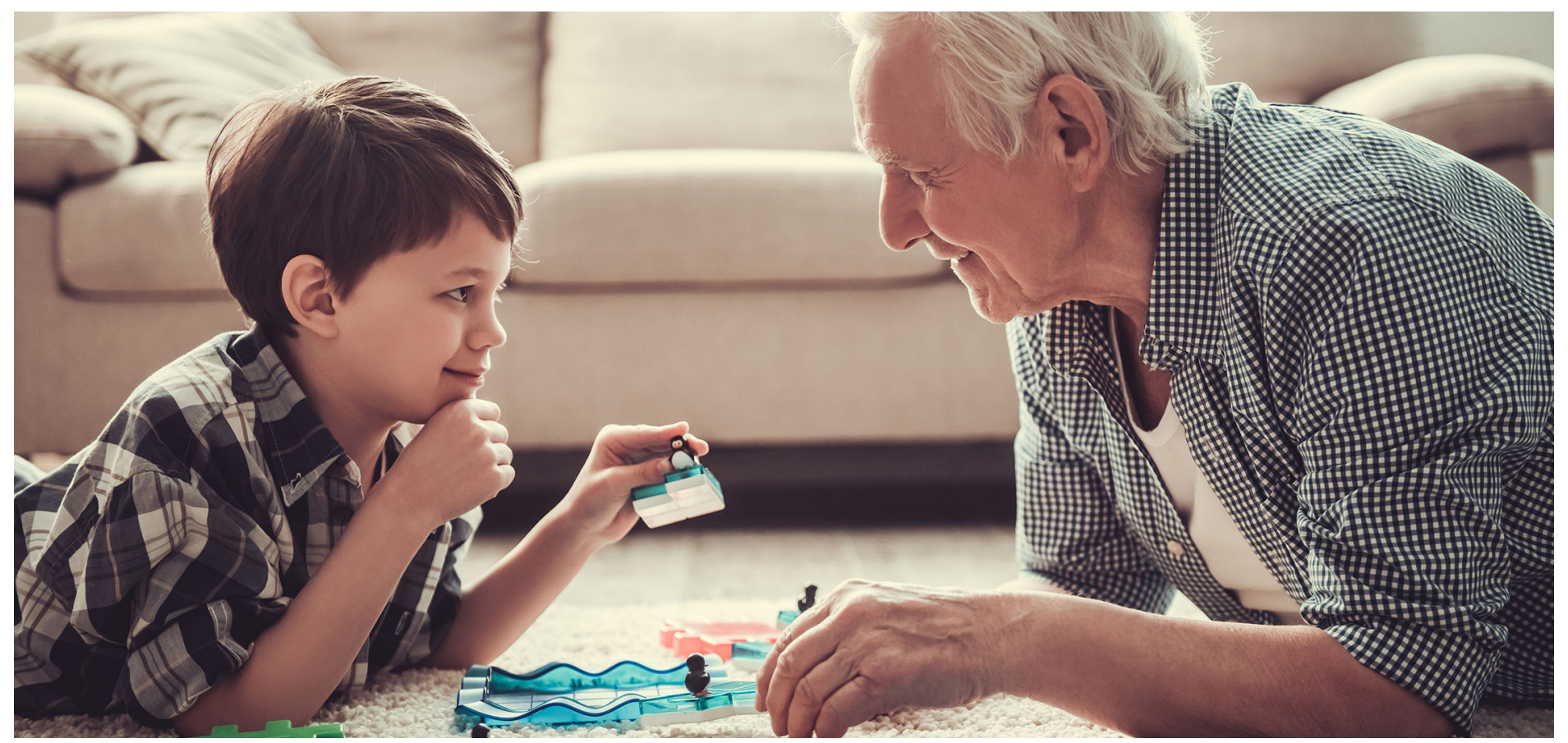

47. AARP Thought Leadership. "Building Equity in Longevity. "Washington, DC: AARP Thought Leadership, May 2021. https://doi.org/10.26419/int.00048.001

48. 2020 Census Statistics Highlight Local Population Changes and Nation's Racial and Ethnic Diversity August 12, 2021.

https://www.census.gov/newsroom/press-releases/2021/population-changes-nations-diversity.html

Our Collective Future: The Economic Impact of Unequal Life Expectancy 


\section{Appendix 1: Expanded notes on the methodology}

The analysis measures the total cost of racial/ethnic disparities in life expectancy by estimating the size of the gap between two contrasting scenarios:

1. Baseline scenario: a decade (2022-2030) with no change to projected disparities, versus

\section{Counterfactual scenario:}

a decade with fully equal life expectancy outcomes between the racial/ethnic groups.

The analysis for this report treats the life expectancy of each gender separately. Four racial/ethnic groups were used in the data modeling: Black people (NonHispanic Black people), White people (Non-Hispanic White people), Latino people (Hispanic people of all races), and "other Non-Hispanic" people. The final group encompasses Asian Americans, Native Americans Native Hawaiians and Pacific Islanders, Native Americans, multiracial people, and all others. These groups were not included as separate categories in this analysis because of limitations in the data and models used.

The counterfactual "full equality" scenario assumes that each of these four groups would have an equally high level of life expectancy. This ideal or aspirational level/age is defined as the number of years a person could expect to live if-during each year of life-that person had the same mortality risk as the best-performing demographic group at each age.
The scenario was constructed using the REMI PI+ model. This model relies on demographic data, including agespecific mortality rates and population projections, from sources such as the U.S. Census, Centers for Disease Control and Prevention, the Bureau of Labor Statistics, and others.

Key factors that were considered in the scenario include the following:

- Age-specific mortality rates and life expectancies were adjusted across the population to be equivalent to those of the best-performing group by race/ethnicity and year of age (each gender treated separately). This is not necessarily the same group at each age.

- The equalization was implemented from year 2022 onward, aiming to create a scenario in year 2030 in which the U.S. had experienced an extended period of equality. This length of time is enough for the economy under this counterfactual scenario to have reached a new equilibrium, allowing for more effective comparison against the baseline status quo.
- Corresponding effects on the timing of retirement and the extent of labor force participation were incorporated for each age, race/ ethnicity, and gender, based on assumptions from the academic literature. The analysis focuses on how higher life expectancy contributes to the aspiration or opportunity to work, rather than creating a need to extend one's working life.

- Following the lead of researchers at NBER and others, the index was set to eight months of additional labor force participation per one year of additional life expectancy. This maintains one's share of life spent in work vs. in retirement at roughly the same ratio (2:1).

- In determining this amount, we used the increase in life expectancy as measured at each age $X$ (as opposed to at birth). This ensures proper correspondence with workers' expectations/circumstances at the age when they would be making retirement decisions.

- The resulting increases to the labor force participation rate (across age and gender cohorts), are broadly in line with previous research from the Federal Reserve on the historical effects of changes in life expectancy at age 65 on the labor force participation rate among older adults. 
- Resulting effects on the composition of the labor force and the average compensation rate in the U.S. were incorporated into the model, based on data from the U.S. Census.

- In our scenario, with a labor force comprising a greater proportion of older workers, we expect the average U.S. wage to be different.

- Using U.S. Census data on average wages-disaggregated by age and gender-we constructed a weighted index to calculate the estimated percent change to the U.S. average wage rate given an older workforce. The resulting change to the U.S. average wage rate used in our final model was minimal $(+0.18$ percent in 2022, declining thereafter throughout the forecast period).
- Changes in personal income, transfer payments, and spending patterns were also incorporated into the model, corresponding to the altered U.S. demographic and economic environment. These changes are calculated automatically in the REMI model, based on the aforementioned changes to demographic and economic baselines.

- The model incorporated the most current available data on survival rates during COVID-19 from the Centers for Disease Control, updated in summer 2020, and these were projected forward based on best estimates at the time. While mortality during the pandemic turned out to be worse than expected, our analysis is not significantly affected by this, as our counterfactual scenario does not commence until the year 2022 (once mortality rates will largely have returned to their typical levels). 
www.aarp.org/longevityeconomy 